\title{
PERFIL DOS PROPRIETÁRIOS DE CÃES E GATOS EM UMA REGIÃO DO MUNICÍPIO DE JABOTICABAL/SP
}

\author{
OWNER'S PROFILE OF DOG AND CAT IN ONE REGION IN THE CITY OF \\ JABOTICABAL, SÃO PAULO
}

\author{
A. P. R. GRISOLIO ${ }^{1}$, M. A. C. PICINATO ${ }^{1 *}$, G. V. LEÃO ${ }^{2}$, J. H. BEGALI ${ }^{1}$, A. A. B. CARVALHO ${ }^{3}$
}

\begin{abstract}
RESUMO
O trabalho objetivou caracterizar o perfil dos proprietários de cães e/ou gatos do bairro Jardim das Rosas, no Município de Jaboticabal/SP, com relação ao conhecimento sobre a transmissão de zoonoses e à guarda responsável de seus animais. Os dados foram obtidos por meio de entrevistas nas residências do bairro Jardim das Rosas, no Município de Jaboticabal/SP, no período de outubro de 2014. Os moradores responderam a questionários semiestruturados sobre o conhecimento que possuem a respeito de zoonoses e dos cuidados que costumam ter com os seus animais de estimação (cães e/ou gatos). As informações foram organizadas em um banco de dados no programa Microsoft Excel®, para que fossem feitas as análises necessárias ao estudo e posterior caracterização do perfil dos proprietários. Entrevistaram-se moradores de 159 residências (1 pessoa/residência); 120 dos munícipes entrevistados possuíam animais de estimação (cães e/ou gatos). Sobre a possibilidade de cães e gatos transmitirem doenças, $73 \%$ afirmaram "sim"; $81 \%$ levavam o seu animal para o atendimento em um médico veterinário. No bairro, havia 215 cães e 64 gatos e uma proporção de 2 cães/residência e 0,5 gato/residência; 24\% (28/120) dos proprietários disseram ter animais que tiveram pelo menos uma cria, obtendo-se uma média de 5,4 filhotes/animal em 2014; 68\% dos animais saíam às ruas, e destes, 66\% (96/146) saíam sem o uso de coleiras com guias, e 40\% (58/146) não eram castrados.Diante dos resultados encontrados, é possível observar riscos potenciais para a saúde pública e a necessidade de promoção de programas de educação em saúde para os moradores no Município de Jaboticabal/SP. Os dados permitem apontar os principais problemas e auxiliar na instituição das ações dos Serviços de Vigilância em Saúde e Epidemiológica, contribuindo de forma ativa para a promoção de saúde e prevenção de enfermidades.
\end{abstract}

PALAVRAS-CHAVE: GUARDA RESPONSÁVEL. ZOONOSES. SAÚDE PÚBLICA.

AGRADECIMENTOS: CAPES

ÁREA TEMÁTICA: SAÚDE PÚBLICA 